\title{
Radiologic Evaluation of Odontometric and Osteologic Traits for Gender Determination in Adult Ethnic Tamil Population
}

\author{
Ramya Mahalingam*, Ramya Ramadoss, Swarna Lakshmi R, \\ Preethi Arunachalam, Amritha James and Lekshmy Jeyan
}

Department of Oral Pathology, Microbiology and Forensic Odontology, SRM Dental College, BharathiSalai, Ramapuram, Chennai 600 089, Tamil Nadu, India; ramyaboho3@gmail.com

\begin{abstract}
Background: Odontometric and osteologic traits have always served as an excellent resource in anthropological, genetic, odontologic, and forensic investigations. Aim: The aim of this study was to find the most reliable method for gender determination by correlating both the odontometric and osteologic variables. Materials and Methods: A retrospective study was conducted using digital panoramic radiographs of 400 individuals ( 200 males and 200 females) with age ranging from 20 to 50 years. Standardized digital panoramic radiographs of patients taken as part of pretreatment planning for implants, extractions of third molars, and for periodontal diseases were selected from the archives. Measurements were done using IMAGE Pro software. Results: Mesiodistal width of 17-47 exhibited significant gender variation. Osteologic parameters such as ramus dimension and the gonial angle also showed significant gender variation and the mandibular asymmetry was significant in both the genders. Conclusion: Correlation of the two group of traits showed strong positive predictive values attributable for gender determination.
\end{abstract}

Keywords: Anthropometry, Gender determination, Odontometric, Osteologic, Panoramic Radiograph

Article chronicle: Date of Submission: 19.09.2019; Date of Acceptance: 23.02.2020; Date of Publication: 24.04.2020)

\section{Introduction}

Gender determination is a subdivision of forensic odontology, and it is very important especially when information relating to the deceased is unavailable. ${ }^{1}$ Gender determination becomes the first priority in the process of identification of a person by a forensic investigator in the case of mishaps, chemical and nuclear bomb explosions, natural disasters crime investigations, and ethnic studies. Because teeth can persist long after other skeletal structures have succumbed to organic decay or destruction of elements, such as fire, teeth play a crucial role in the gender determination as they still remain the same with minimal changes. ${ }^{2,3}$ Being the most indestructible part of the body and exhibiting the least turnover of natural structure, they not only survive death, but also remain relatively unchanged for many years. It is important for a trained forensic odontologist to identify the gender from whatever human dental remains are presented to them as a specimen. ${ }^{4}$

The skull being the most dimorphic and easily sexed portion of skeleton after pelvis it can provide indispensable information to identify the sex of the patient. However, in some instances, the availability of the intact skull is quite toilsome. In such cases, the mandible may play a vital role in gender determination, as it is the most dimorphic, largest, and strongest bone of the skull that is often recovered largely intact. ${ }^{5}$ The existence of sexual dimorphism in permanent teeth is a known phenomenon, as observed in several investigations. This, therefore, has a great significance in forensic medicine. Thus, measuring the mesiodistal width of all the teeth is

*Author for correspondence 
a valuable odontometric method of estimating the gender of the patient. ${ }^{6}$ In the same way, ramus can differentiate between sexes, as the stages of mandibular development, growth rates, and duration are distinctly different in both sexes. There are different factors that form the basis for the changes in the mandible and dimensions attributed for gender determination. Various parameters such as gonial angle, mandibular asymmetry, and ramus height can be used as the osteologic method for gender determination. ${ }^{4-6}$

The accuracy of gender determination by using postmortem radiographs, long-bone dimensions, pelvic structures, and so on, ranges from $96 \%$ to $100 \%$. In forensic anthropology, comparison of antemortem and postmortem radiographs is a cardinal tool to proffer a valuable data in gender determination.

Panoramic radiographs are commonly accessible and are used in daily clinical practice to assess mandibular vital structures bilaterally., ${ }^{7,8}$ Some studies had concluded that the most reliable panoramic measurements were obtained of linear objects in the horizontal plane. Moreover, other studies had shown that the vertical measurements had acceptable accuracy and reproducibility when a software-based calibrated measurement tool was used. The presence of plenty of panoramic radiographs provides a great opportunity to study the sexual dimorphism among individuals in a certain population. ${ }^{8,9}$

Therefore, the purpose of the present study was to evaluate and correlate the odontometric and osteologic traits among the ethnic Tamil population.

\section{Materials and Methods}

A retrospective study was conducted using digital panoramic radiographs of 400 individuals (200 males and 200 females) with age ranging from 20 to 50 years. Standardized digital panoramic radiographs of patients taken as part of pretreatment planning for implants, extractions of third molars, and for periodontal diseases were selected from the archives of the radiology department. The inclusion and exclusion criteria are tabulated in Table 1.

The files received in JPEG format were then standardized with the standard values for width and height of the radiographs. The mesiodistal width of the tooth was then assessed as a part of odontometric traits using IMAGE PRO software (Media Cybernetics,
Rockville, Maryland, USA). The gonial angle, mandibular ramus height, and mandibular asymmetry were then assessed as a part of osteologic trait using IMAGE PRO software.

\section{Assessment of Odontometric Traits Measurement of mesiodistal width of all the teeth} Mesiodistal width measurement was done using the IMAGE PRO software by drawing a linear line at the middle third of the tooth. This procedure was repeated for each tooth for both maxillary and mandibular quadrants. Each tooth was measured separately and finally summed up altogether as a block from 17 to 47 [Figure 1].

\section{Assessment of Osteologic Traits Measurement of gonial angle}

The measurement of gonial angle was done using the line of intersection between a digitally traced line tangential to the most inferior points at the angle and the lower border of the mandibular body and another line tangential to the posterior borders of the ramus and the condyle [Figure 2].

\section{Measurement of Ramus Height}

Condylar ramus height ( $\mathrm{a}$ and $\mathrm{b}$ ): The distance from the condylion (a) to the intersection of the orientation line with the inferior border of the ramus (b) [Figure 3].

Coronoid ramus height ( $c$ and $b$ ): The distance between coronion (c) and the intersection of the orientation line with the inferior border of the ramus (b) [Figure 4].

The collected data are tabulated in Table 2 .

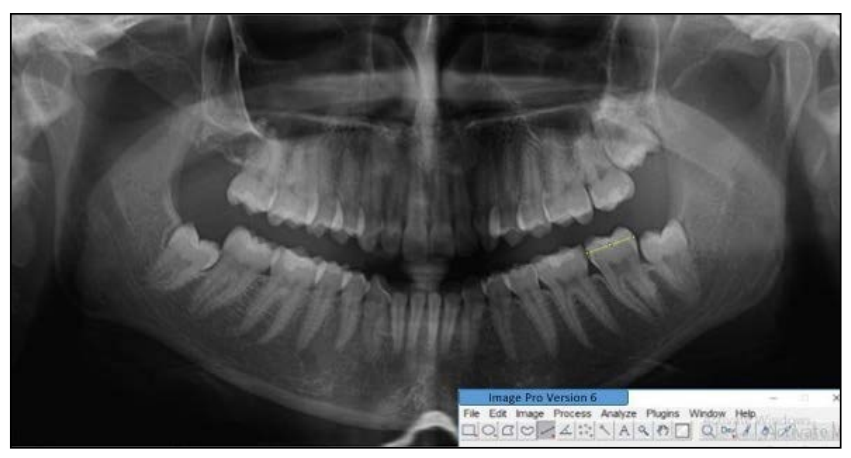

Figure 1: Mesiodistal width of the tooth measured using a measuring tool in IMAGE PRO software. 


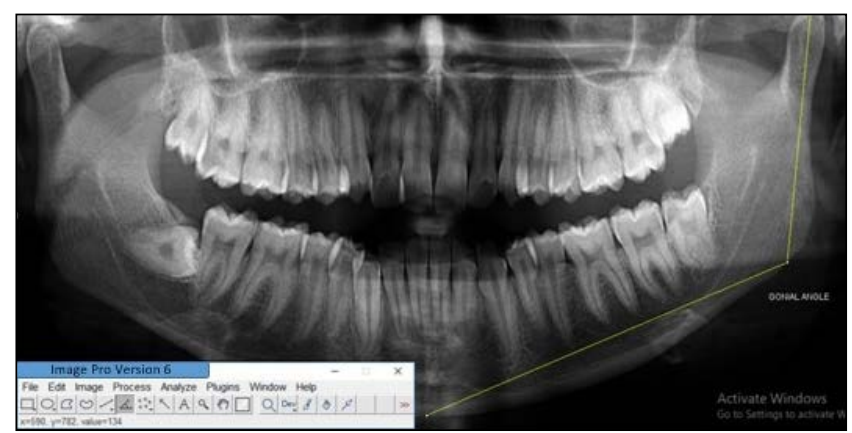

Figure 2: Gonial angle measured using angle measurement tool.

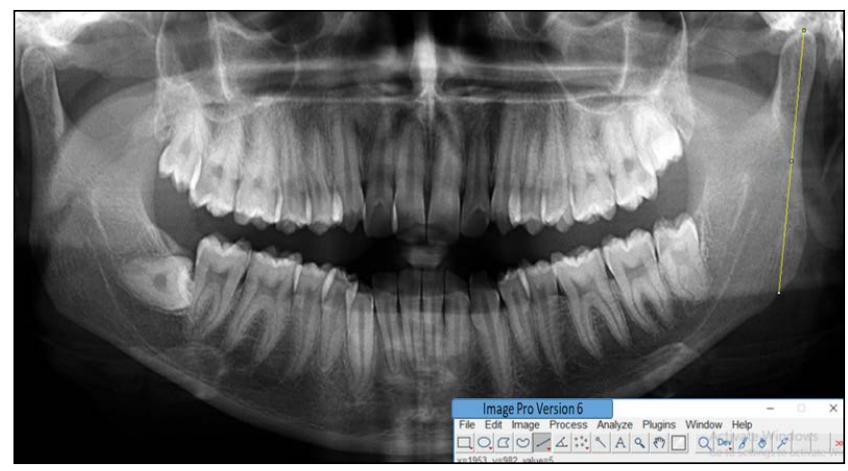

Figure 3: Measurement of condylar ramus height using the measuring tool.

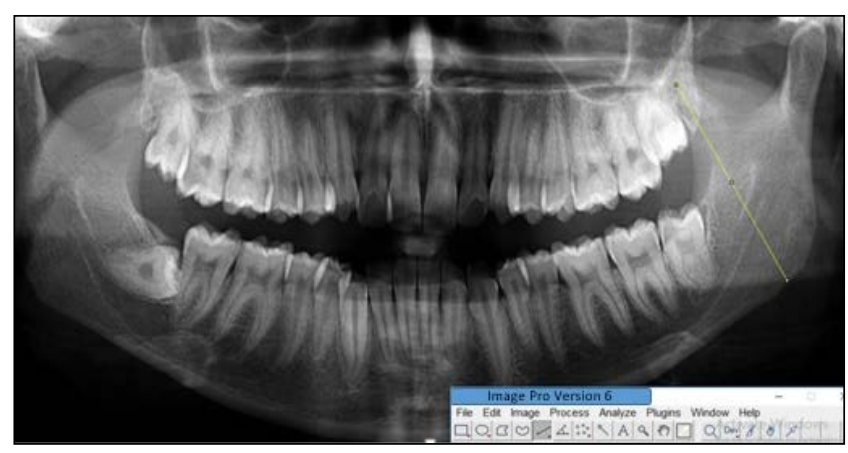

Figure 4: Measurement of coronoid ramus height using the measuring tool.

\section{Statistical Analysis}

The range, mean, and standard deviation of odontometric and osteologic parameters were calculated and were then subjected to statistical analysis. $t$-test was used to compare the difference of means for both the genders. The difference in means was compared for both males and females separately for each of the osteologic and odontometric parameters. A statistical significance was set at $P<0.05$.
Table 1. Inclusion and exclusion criteria

\begin{tabular}{ll}
\hline Criteria & Patients included/excluded \\
\hline Inclusion criteria & Patients within the age group of 20-50 years \\
& $\begin{array}{l}\text { Permanent teeth of the maxillary and } \\
\text { mandibular jaws with intact mesiodistal } \\
\text { diameter of the crown, teeth with no gross } \\
\text { dental abnormalities }\end{array}$ \\
& $\begin{array}{l}\text { Panoramic images without distortion and } \\
\text { positioning errors }\end{array}$ \\
Exclusion criteria & $\begin{array}{l}\text { Patients with alteration in the number or } \\
\text { shape of the teeth }\end{array}$ \\
& Images with poor quality \\
& Presence of any pathological lesions, \\
& fracture, or deformity and panaromic \\
& images with name and age mentioned in \\
& the image
\end{tabular}

Table 2. Results of mesiodistal width

\begin{tabular}{lccc}
\hline Gender & Average & Standard deviation & $P$ \\
\hline Male & 650.45 & 40.61 & $<0.05$ \\
Female & 620.51 & 38.71 & Significant \\
\hline
\end{tabular}

Table 3. Results of gonial angle

\begin{tabular}{lccc}
\hline Gender & Mean & Standard deviation & $\mathbf{P}$ \\
\hline Male & 121.42 & 5.60 & $<0.05$ \\
Female & 162.97 & 7.56 & Significant \\
\hline
\end{tabular}

Table 4. Results of ramus height

\begin{tabular}{lccc}
\hline Gender & Mean & Standard deviation & $\mathbf{P}$ \\
\hline Male & 163.00 & 7.56 & $0.78(>0.05)$ \\
Female & 162.55 & 7.45 & Insignificant1 \\
\hline
\end{tabular}

Table 5. Percentage of mandibular asymmetry

\begin{tabular}{lc}
\hline Gender & \% of mandibular asymmetry \\
\hline Male & 64 \\
Female & 64.2 \\
\hline
\end{tabular}

\section{Results}

An observational study was conducted with 400 panoramic radiographs obtained from archives to determine the correlation between odontometric and osteologic traits and establishing a standard method for gender determination using $t$-test.

The odontometric variable, the mesiodistal dimension of all the teeth, was measured from 17 to 47 , and the 
mean values for maxillary and mandibular arches were measured [Table 2]. The mean of mesiodistal width of male population (650.45) compared to female populaion (620.51) with standard deviation of both being 40.61 and 38.71 , respectively.

The osteologic variable, the gonial angle, in females was higher when compared to that of males with the mean angle of 162.97 and 121.42 with significant $P$ value, which is tabulated in Table 3. The osteologic variable, the ramus height measurement, did not show significant variation, with insignificant $\mathrm{P}$ value as tabulated in Table 4 . The ramus height was almost the same in both the genders. The mandibular asymmetry was equally present in both the genders with $0.2 \%$ increase in female population, as tabulated in Table 5. This was assessed to identify the escalation in the incidence of mandibular asymmetry among the male and female individuals.

\section{Discussion}

Many observational studies and cross-sectional studies have documented the significance of odontometric method in the identification of the deceased individual. The variety and uniqueness of the teeth, number, and morphology in each individual, is a fact that increases its importance as an identifying element. Teeth are known to be unique structures made of the most enduring mineralized tissues in the human body. ${ }^{6,10,11}$ As such, teeth are resistant to mechanical, chemical, physical, and thermal types of destruction. ${ }^{6}$ Therefore, teeth are very important elements in the identification of skeletal remains, especially in cases when there is poor preservation of skeletal remains that the identification is not possible by the standard methods. Thus, assessing the odontometric parameters offers an optimal method for gender determination. ${ }^{2,12,13}$

The odontometric variations are looked for in forensic sciences when the most reliable parameters for gender determination such as pelvic bone and long bones are lost. So far, the odontometric variations in population have been used for the gender determination and age estimation. ${ }^{12}$ Rothwell et al. described the various principles of the dental identification that help in the identification of the deceased individual and highlighted the crucial role played by the forensic dentist when other information is lost. ${ }^{14}$
Osteological variations such as gonial angle and ramus height are chiefly used for the age estimation. Incorporating these parameters for the gender determination showed significant variations. ${ }^{15} \mathrm{~A}$ similar study by Takahiro et al. studied gonial angle, mandibular ramus morphometry, ramus cortical index (rci), notch depth, and ascending ramus. ${ }^{16}$ They emphasized that gonial angle can be used as the important parameter in gender determination. ${ }^{11,16}$ Not only in gender determination but also in age estimation the gonial angle plays an important role and is considered as a vital tool in forensic sciences. ${ }^{11}$

Gender determination by various methods such as visual assessment of sexually dimorphic features has proved to be of prime importance. The alternative techniques to visual assessment namely the metric approaches for gender determination has taken over the visual assessment when comes to reliability and accuracy. ${ }^{17}$ Mesiodistal width of the permanent teeth, mostly the canine, is the most commonly used and researched tooth in the estimation of gender.

Studies on sexual dimorphism of teeth have reported that the permanent teeth are highly dimorphic, and the measurement of odontometric and osteologic parameters and correlation of the same will be considered as a more reliable tool than to assess them as two different variables. Macaluso highlighted the pivotal role played by maxillary molars in gender determination and concluded by saying that the maxillary first and second molars can be used as a reliable tool in the gender determination. ${ }^{18}$

Thus, the aim of this study was to find the most reliable method for gender determination by correlating both the odontometric and osteologic variables in gender determination. These findings showed that the male population showed increased mesiodistal dimension when compared to that of the female population; similar results were compiled by many authors wherein the mesiodistal and buccolingual width of the males were higher than that of the females. ${ }^{2,11,12}$

Similar to the odontometric methods, the studies conducted on the anatomical landmarks in mandible in the absence of pelvic bone and few other long bones have stated that the anatomical landmarks in the mandible are standardized, well defined, and easy to locate. In a study conducted by Abu-Taleb and El Beshlawy among the Egyptian population, it was found that the mandibular ramus showed a high sexual dimorphism and proved to be beneficial in sex and age estimation, while the gonial angle could assist in sex estimation only. ${ }^{4}$ This study 
also used the panoramic radiographs for the assessment of the gonial angle and the mandibular parameters and concluded that panoramic radiographs can be used for the assessment of the above parameters. Moreover, few other studies have also discussed the effectiveness of the osteologic parameters in racial differentiation among people of a particular geographic distribution. ${ }^{19-21}$ There are few literatures which studied the gender determination potential of these osteologic parameters. Another study conducted by Samatha et al. highlighted that mandibular ramus height showed significant gender variations and the study was conducted with the help of orthopantomographs. Determining the sex of an individual with the help of panoramic radiographs was found to be a reliable method. ${ }^{21}$

Osteologic parameters such as gonial angle showed significant gender variations, in which the female population showed increased gonial angle when compared to the male population. Thus, measuring the gonial angle will serve as one of the important tools in gender determination, however the ramus height did not show any gender variation where the $\mathrm{P}$ value was not significant. In addition, the ramus height assessment was considered to be of superior value owing to their objectivity, accuracy, and reproducibility.

Thus, for the above-discussed parameters, the statistical analysis was done and the mean and standard deviation was calculated. The mean of mesiodistal width of male population was found to be higher than that of the female population. The gonial angle in females was higher when compared to that of the males, and thus the present study has found that with significant $\mathrm{P}$ value, it can also be used as an important tool in gender determination [Table 4]. Finally, on combing the odontometric and osteologic traits, gender discrimination can be done more effectively. Thus, the correlation of odontometric and osteologic traits showed strong positive predictive values attributable for gender determination.

Considering the mandibular asymmetry, it was equally prevalent among both the population. No particular gender showed higher incidence of mandibular asymmetry.

This study is the first of its kind which is an extensive effort to correlate the odontometric and osteologic parameters in an attempt at standardization.

\section{Conclusion}

Gender determination using teeth is an inexpensive and easy method of gender identification from fragmented jaws and dental remains. The results of the present study revealed that the mesiodistal width of all the teeth exhibited significant gender variation. Osteologic parameters such as the gonial angle also showed significant gender variation. The mandibular asymmetry was significant in both the genders. Correlation between the odontometric and osteologic trait showed strong positive predictive values attributable for gender determination. These findings could be used as adjuncts for the estimation of gender in individuals, as well as in groups, such as in mass disasters and archaeological sites.

\section{Financial Support and Sponsorship}

Nil.

\section{Conflicts of Interest}

There are no conflicts of interest.

\section{References}

1. Rajendran R, Sivapathasundaram B. Shafer's Textbook of Oral Pathology. 6th ed. India: Elseveir; 2009.

2. Khangura RK, Sircar K, Singh S, Rastogi V. Sex determination using mesiodistal dimension of permanent maxillary incisors and canines. J Forensic Dent Sci 2011;3:81-5.

3. Gupta M, Srivastava R, Jyoti B, Jha P, Jayaram R, Devi P. Gender determination from the mesiodistal dimension of permanent maxillary incisors and canines: An odontometric study. J Indian Acad Oral Med Radiol 2014;26:287.

4. Abu-Taleb NS, El Beshlawy DM. Mandibular ramus and gonial angle measurements as predictors of sex and age in an Egyptian population sample: A digital panoramic study. J Forensic Res 2015;6:1.

5. Maloth KN, Kundoor VK, Vishnumolakala SS, Kesidi S, Lakshmi MV, Thakur M. Mandibular ramus: A predictor for sex determination-A digital radiographic study. J Indian Acad Oral Med Radiol 2017;29:242.

6. Grover M, Bai RG, Ram T, Puri PM, Ghodke KR. An odontologist's key to sex determination: study analysis of mandibular canine teeth in South Indian population. J Orofac Res 2013:157-60. 
7. Rajathi JM, Ramasamy S, Austin R, Mathew P. Validation of dental panoramic radiographs for the localization of impacted maxillary canines. Indian J Oral Sci 2014;5:10.

8. Choi BR, Choi DH, Huh KH, Yi WJ, Heo MS, Choi SC, et al. Clinical image quality evaluation for panoramic radiography in Korean dental clinics. Imaging Sci Dent 2012;42:183-90.

9. Lucchesi MV, Wood RE, Nortjé CJ. Suitability of the panoramic radiograph for assessment of mesiodistal angulation of teeth in the buccal segments of the mandible. Am J Orthod Dentofac Orthop 1988;94:303-10.

10. Thapar R, Angadi PV, Hallikerimath S, Kale AD. Sex assessment using odontometry and cranial anthropometry: Evaluation in an Indian sample. Forensic Sci Med Pathol 2012;8:94-100.

11. Jawaid M, Amir A, Shahnawaz K, Qamar Y, Upadhay P, Singh J. Maxillofacial Imaging in Forensic Science: A Newer Approach. Int J Contemp Med Res ISSN 2016;43:2393-915.

12. Singh SK, Gupta A, Padmavathi BN, Kumar S, Roy S, Kumar A. Mandibular canine index: A reliable predictor for gender identification using study cast in Indian population. Indian J Dent Res 2015;26:396-9.

13. Macaluso PJ Jr. Sex discrimination potential of permanent maxillary molar cusp diameters. J Forensic Odontostomatol 2010;28:22-31.

14. Rothwell BR. Principles of dental identification. Dent Clin North Am 2001;45:253-70.
15. Upadhyay RB, Upadhyay J, Agrawal P, Rao NN. Analysis of gonial angle in relation to age, gender, and dentition status by radiological and anthropometric methods. J Forensic Dent Sci 2012;4:29-33.

16. Ogawa T, Osato S, Shishido Y, Okada M, Misaki K. Relationships between the gonial angle and mandibular ramus morphology in dentate subjects: A panoramic radiophotometric study. J Oral Implantol 2012;38:203-10.

17. Astete JC, San Pedro VJ, Suazo GI. Sexual dimorphism in the tooth dimensions of Spanish and Chilean peoples. Int J Odontostomat 2009;3:47-50.

18. Macaluso PJ Jr. Investigation on the utility of permanent maxillary molar cusp areas for sex estimation. Forensic Sci Med Pathol 2011;7:233-47.

19. Suragimath G, Ashwinirani SR, Christopher V, Bijjargi S, Pawar R, Nayak A. Gender determination by radiographic analysis of mental foramen in the Maharashtra population of India. J Forensic Dent Sci 2016;8:176.

20. Gupta S, Jain S. Orthopantomographic analysis for assessment of mandibular asymmetry. J Indian Orthod Soc 2012;46:33-7.

21. Samatha K, Byahatti SM, Ammanagi RA, Tantradi P, Sarang CK, Shivpuje P. Sex determination by mandibular ramus: A digital orthopantomographic study. J Forensic Dent Sci 2016;8:95-8
How to cite this article: Mahalingam $R$, Ramadoss $R$, Lakshmi $\mathrm{SR}$, Arunachalam P, James A and Jeyan L. Radiologic Evaluation of Odontometric and Osteologic Traits for Gender Determination in Adult Ethnic Tamil Population. J Forensic Dent Sci 2020;12(1):50-55.

\begin{tabular}{|l|c|}
\hline \multicolumn{2}{|c|}{ Access this article online } \\
\hline \multirow{3}{*}{ Website: } & Quick Response Code \\
www.jfds.org & \\
&
\end{tabular}

